\title{
Breastfeeding, Human Milk and COVID-19-What Does the Evidence Say?
}

\author{
Leon R. Mitoulas $^{1,2 *}$, Nania G. Schärer-Hernández ${ }^{1}$ and Severine Liabat ${ }^{1}$ \\ ${ }^{1}$ Medela AG, Baar, Switzerland, ${ }^{2}$ Honorary Research Fellow, School of Molecular Sciences, The University of Western \\ Australia, Perth, WA, Australia
}

Keywords: human milk, breast milk, breastfeeding, coronavirus, COVID-19, SARS-CoV-2, transmission, evidence

\section{INTRODUCTION}

Severe acute respiratory syndrome coronavirus 2 (SARS-Cov-2), the virus responsible for COVID-19, is a recently discovered coronavirus that as of October 2020 has reached across the globe infecting over 33 million people, of which approximately 1 million have died (1). Coronaviruses are a large family of viruses known to cause respiratory infections in humans. These viruses also include Middle East Respiratory Syndrome (MERS) and Severe Acute Respiratory Syndrome (SARS).

The most common symptoms associated with COVID-19 are fever, dry cough, and tiredness.

OPEN ACCESS

Edited by:

Sven Wellmann

University of Regensburg, Germany

Reviewed by:

Sara Fill Malfertheiner,

University of Regensburg, Germany

Eric Giannoni,

Centre Hospitalier Universitaire

Vaudois (CHUV), Switzerland

*Correspondence:

Leon R. Mitoulas

leon.mitoulas@medela.com

Specialty section:

This article was submitted to

Neonatology,

a section of the journal

Frontiers in Pediatrics

Received: 02 October 2020

Accepted: 28 October 2020

Published: 20 November 2020

Citation:

Mitoulas LR, Schärer-Hernández NG and Liabat S (2020) Breastfeeding,

Human Milk and COVID-19-What

Does the Evidence Say?

Front. Pediatr. 8:613339.

doi: 10.3389/fped.2020.613339
Other less common symptoms include nasal congestion, headache, conjunctivitis, sore throat, diarrhea, loss of taste or smell and general aches and pains. Importantly, some people may experience very mild symptoms whereas others, especially those with existing underlying medical problems, e.g., high blood pressure, heart and lung problems, diabetes, or cancer, are at a higher risk of serious illness and potentially death (2).

As the pandemic unfolded, many questions were asked with respect to transmission routes and modes of infection, with particular interest devoted to the mother-infant dyad and the status of breastfeeding and human milk. Whilst the benefits of human milk and breastfeeding to the mother and the infant are well-documented (3) there was uncertainty in the early stages of the pandemic with respect to hospital practices and recommendations. What was clear, however, was the need for evidence-based recommendations addressing the issue of transmission whilst accounting for the value of breastfeeding. Such recommendations would enable new mothers and their babies to continue benefitting from the advantages of breastfeeding and the use of human milk in this COVID-19 era.

\section{HORIZONTAL TRANSMISSION}

The primary mode of transmission of SARS-CoV-2 is horizontal transmission via direct, indirect, or close contact with infected people through secretions, such as saliva or respiratory droplets, expelled during talking, coughing, and/or sneezing (4). These respiratory droplets or aerosols may be the source of transmission via either airborne routes or from surface contact. Whilst airborne routes of transmission might be limited (5), aerosols and droplets can remain viable on surfaces such as cardboard, plastic, and stainless steel for up to $72 \mathrm{~h} \mathrm{(6).}$

Of particular interest is the ability to transmit the virus via other biological fluids. Active virus has been found in fecal samples and evidence of viral RNA has been observed in blood (7). Furthermore, viral RNA has been isolated from urine (8). However, it must be noted that to date there have been no reports of transmission via feces $(9,10)$ or urine $(4)$ or via blood transfusion $(9,10)$. 


\section{VERTICAL TRANSMISSION}

The transmission of SARS-CoV-2 from mother to infant, vertical transmission, has been the source of intense scrutiny, and can be categorized as intrauterine/congenital, intrapartum, or postnatal $(11,12)$. To date, reports of intrauterine, or transplacental transmission have been described $(13,14)$, although cases in the literature are limited. Bwire et al. (15) summarized the findings from 205 infants born to mothers positive for COVID-19 and found that $6.3 \%$ of infants were infected. Transmission was reported for term and preterm infants and for vaginal and c-section modes of delivery. These data were supported by other reviews which concluded that neonatal COVID-19 infection is uncommon, almost never symptomatic, and that the rate of infection is no greater when the baby is born vaginally, breastfed, or allowed contact with the mother $(16,17)$.

Studies on postnatal transmission have focused on accepted contact (horizontal) routes as well as the investigation of vertical routes e.g., via human milk. Whereas, the horizontal transmission routes are well-accepted and characterized, the role that human milk plays, if at all, is still not fully elucidated.

To date, in the literature, there are no confirmed reports of postnatal transmission of SARS-CoV-2 via human milk. Whereas, a recent report did not detect any SARS-CoV-2 in milk samples collected from women with mild to moderate COVID19 symptoms (18), some earlier reports in the literature have noted the presence of SARS-CoV-2 viral RNA in human milk (19-25). However, in none of these cases there was evidence that the virus was complete and/or active. It is also of note that only random milk samples were shown to be positive for viral RNA. For example, in the study conducted by Chambers et al. (23) only one milk sample from one mother on 1 day was positive. Milk samples from the same mother 2 days prior and 12 days later were negative. Similar transient positive identification of viral RNA in human milk has also been observed in other studies $(20,24)$. As such, the researchers could not rule out contamination of the milk via respiratory droplets from the mother as a possible explanation for the detection of viral RNA in the breast milk samples analyzed. Whilst continued research is required to better characterize the presence of the virus in human milk, current evidence suggests that human milk does not appear to play a role in the transmission of SARS-CoV-2 $(26,27)$.

Despite the limited reports documenting the presence of viral RNA in human milk and the lack of any data showing the presence of active virus, several studies have investigated the ability of pasteurization techniques to destroy the virus. All have shown that Holder Pasteurization $\left(62.5^{\circ} \mathrm{C}\right.$ for $\left.30 \mathrm{~min}\right)$ is able to inactivate replication-competent SARS-CoV-2 virus that had been added into human milk samples in the laboratory $(23,28$, 29). As Holder Pasteurization is the main method employed by milk banks, it confirms that Pasteurization of human milk is a safe and feasible option if the clinician or mother are in any doubt with respect to the continued feeding of the infant with human milk upon a positive SARS-CoV-2 infection of the mother.

\section{DISCUSSION}

As the evidence currently suggests, there is limited risk that SARS-CoV-2 can be transmitted via human milk. Consequently, the WHO (30) and other organizations [e.g., UNICEF (31), CDC (32), Royal College of Obstetricians and Gynaecologists (33)] recommend that mothers continue to breastfeed their infants. Indeed, the main concern in this instance is the mother's ability to follow the strict contact precautions to avoid spreading the virus via the recognized horizontal routes. Therefore, it is important that mothers be counseled on suitable protocols for breastfeeding and breast pump usage $(12,17,26,32)$.

The importance of the continuity of breastfeeding for the infant in these times cannot be overstated. In addition to the already well-known and documented benefits of breastfeeding (3), recent research has shown specific benefits relevant to the COVID-19 situation. For example, antibodies to SARS-CoV-2 have recently been isolated in human milk (34-36) and have shown strong SARS-CoV-2 neutralizing capabilities $(18,37)$. Whilst these data show a robust immunological response by human milk against the virus they also suggest that human milk provides an active form of protection against the virus, a form of protection that cannot be provided to the infant via artificial formula, thus further supporting the need for the protection and promotion of breastfeeding.

Despite the many general benefits of breastfeeding to the infant, as well as the potential COVID-19 specific immunological benefits, recent research has also highlighted the need to be aware of maternal mental health in relation to the COVID-19 pandemic. A survey of over 5,000 women in Belgium, showed an increased likelihood of anxiety among pregnant women and early postpartum mothers during the recent COVID-19 lockdown (38). Similar outcomes were observed in Italy, which resulted in a worsening of maternal depressive symptoms (39). Importantly, these data were supported by a smaller cohort of mothers in Canada, suggesting that this response is not merely cultural (40). It is well-known that increases in maternal depressive symptoms lead to decreases in breastfeeding confidence and self-efficacy, resulting in reduced breastfeeding duration $(41,42)$. Therefore, it will be important to anticipate these mental health issues for new mothers in this COVID-19 era and provide them with the extra support needed so that their mental health well-being is ensured and that they and their infants continue to benefit from all the advantages afforded through breastfeeding (43).

\section{CONCLUSION}

Despite the relatively short time the research community has had to investigate SARS-CoV-2 and its impact on breastfeeding and human milk, a tremendous volume of work has been conducted and published. These data show no evidence of active virus in human milk and suggest that vertical transmission via breast milk is very unlikely. Furthermore, there is very good evidence that 
antibodies present in human milk can neutralize SARS$\mathrm{CoV}-2$, suggesting a protective role of human milk against infection. These data all suggest that mothers and their infants should be kept together and breastfeeding should be promoted. Indeed, it is the avoidance of the established horizontal transmission routes between a mother and her infant that should be the focus of attention and education. Guidelines and practice recommendations based on these data should be developed in order to promote and protect

\section{REFERENCES}

1. Dong E, Du H, Gardner L. An interactive web-based dashboard to track COVID-19 in real time. Lancet Infect Dis. (2020) 20:533-4. doi: 10.1016/S1473-3099(20)30120-1

2. WHO. Q®A on Coronaviruses (COVID-19). (2020). Available online at: https://www.who.int/emergencies/diseases/novel-coronavirus-2019/ question-and-answers-hub/q-a-detail/q-a-coronaviruses (accessed July 21, 2020).

3. Victora CG, Bahl R, Barros AJD, Franca GVA, Horton S, Krasevec J, et al. Breastfeeding in the 21st century: epidemiology, mechanisms, and lifelong effect. Lancet. (2016) 387:475-90. doi: 10.1016/S0140-6736(15)01024-7

4. WHO. Scientific Brief of the WHO-Transmission of SARS-CoV-2: Implications for Infection Prevention Precautions. (2020). Available online at: https:// www.who.int/news-room/commentaries/detail/transmission-of-sars-cov-2implications-for-infection-prevention-precautions (accessed July 21, 2020).

5. Klompas M, Baker MA, Rhee C. Airborne Transmission of SARS-CoV-2: theoretical considerations and available evidence. JAMA. (2020) 324:4412. doi: $10.1001 /$ jama.2020.12458

6. van Doremalen N, Bushmaker T, Morris DH, Holbrook MG, Gamble A, Williamson BN, et al. Aerosol and surface stability of SARS-CoV2 as compared with SARS-CoV-1. N Engl J Med. (2020) 382:15647. doi: 10.1056/NEJMc2004973

7. Wang W, Xu Y, Gao R, Lu R, Han K, Wu G, et al. Detection of SARSCoV-2 in different types of clinical specimens. JAMA. (2020) 323:18434. doi: 10.1001/jama.2020.3786

8. Sun J, Zhu A, Li H, Zheng K, Zhuang Z, Chen Z, et al. Isolation of infectious SARS-CoV-2 from urine of a COVID-19 patient. Emerg Microbes Infect. (2020) 9:991-3. doi: 10.1080/22221751.2020.1760144

9. Stanworth SJ, New HV, Apelseth TO, Brunskill S, Cardigan R, Doree C, et al. Effects of the COVID-19 pandemic on supply and use of blood for transfusion. Lancet Haematol. (2020) 7:e756-64. doi: 10.1016/S2352-3026(20)30186-1

10. Meyerowitz EA, Richterman A, Gandhi RT, Sax PE. Transmission of SARSCoV-2: a review of viral, host, and environmental factors. Ann Intern Med. (2020). doi: 10.7326/M20-5008. [Epub ahead of print].

11. Blumberg DA, Underwood MA, Hedriana HL, Lakshminrusimha S. Vertical transmission of SARS-CoV-2: what is the optimal definition? Am J Perinatol. (2020) 37:769-72. doi: 10.1055/s-0040-1712457

12. Raschetti R, Vivanti AJ, Vauloup-Fellous C, Loi B, Benachi A, de Luca D. Synthesis and systematic review of reported neonatal SARS-CoV-2 infections. Nat Commun. (2020) 11:5164-73. doi: 10.1038/s41467-020-18982-9

13. Sisman J, Jaleel MA, Moreno W, Rajaram V, Collins RRJ, Savani RC, et al. Intrauterine transmission of SARS-CoV-2 infection in a preterm infant. Pediatr Infect Dis J. (2020) 39:e265-7. doi: 10.1097/INF.0000000000002815

14. Vivanti AJ, Vauloup-Fellous C, Prevot S, Zupan V, Suffee C, Do Cao J, et al. Transplacental transmission of SARS-CoV-2 infection. Nat Commun. (2020) 11:3572-8. doi: 10.1038/s41467-020-17436-6

15. Bwire GM, Njiro BJ, Mwakawanga DL, Sabas D, Sunguya BF. Possible vertical transmission and antibodies against SARS-CoV-2 among infants born to mothers with COVID-19: a living systematic review. J Med Virol. (2020). doi: 10.1002/jmv.26622. [Epub ahead of print].

16. Walker KF, O’Donoghue K, Grace N, Dorling J, Comeau JL, Li W, et al. Maternal transmission of SARS-COV-2 to the neonate, and possible routes breastfeeding and the use of human milk during these unprecedented times.

\section{AUTHOR CONTRIBUTIONS}

LM, NS-H, and SL conceptualized, reviewed, and edited the manuscript. LM drafted the initial manuscript. All authors contributed to the article and approved the submitted version. for such transmission: a systematic review and critical analysis. BJOG. (2020) 127:1324-36. doi: 10.1111/1471-0528.16362

17. Trevisanuto D, Cavallin F, Cavicchiolo ME, Borellini M, Calgaro S, Baraldi E. Coronavirus infection in neonates: a systematic review. Arch Dis Child Fetal Neonatal Ed. (2020). doi: 10.1136/archdischild-2020-319837. [Epub ahead of print].

18. Pace RM, Williams JE, Järvinen KM, Belfort MB, Pace CD, Lackey KA, et al. COVID-19 and human milk: SARS-CoV-2, antibodies, and neutralizing capacity. medRxiv. (2020). doi: 10.1101/2020.09.16.20196071. [Epub ahead of print].

19. Wu Y, Liu C, Dong L, Zhang C, Chen Y, Liu J, et al. Viral shedding of Covid19 in pregnant women. SSRN Electron J. (2020). doi: 10.2139/ssrn.3562059. [Epub ahead of print].

20. Groß R, Conzelmann C, Müller JA, Stenger S, Steinhart K, Kirchhoff F, et al. Detection of SARS-CoV-2 in human breastmilk. Lancet. (2020) 395:17578. doi: 10.1016/S0140-6736(20)31181-8

21. Costa S, Posteraro B, Marchetti S, Tamburrini E, Carducci B, Lanzone A, et al. Excretion of SARS-CoV-2 in human breast milk. Clin Microbiol Infect. (2020) 26:1430-2. doi: 10.1016/j.cmi.2020.05.027

22. Tam PCK, Ly KM, Kernich ML, Spurrier N, Lawrence D, Gordon DL, et al. Detectable severe acute respiratory syndrome coronavirus 2 (SARS-CoV-2) in human breast milk of a mildly symptomatic patient with coronavirus disease 2019 (COVID-19). Clin Infect Dis. (2020). doi: 10.1093/cid/ciaa673. [Epub ahead of print].

23. Chambers C, Krogstad P, Bertrand K, Contreras D, Tobin NH, Bode L, et al. Evaluation for SARS-CoV-2 in breast milk from 18 infected women. JAMA. (2020) 324:1347-8. doi: 10.1001/jama.2020.15580

24. Bertino E, Moro GE, De Renzi G, Viberti G, Cavallo R, Coscia A, et al. SARS CoV-2 in human breast milk and neonatal outcome: a collaborative study. SSRN Electron J. (2020). doi: 10.2139/ssrn.3611974. [Epub ahead of print].

25. Bastug A, Hanifehnezhad A, Tayman C, Ozkul A, Ozbay O, Kazancioglu S, et al. Virolactia in an asymptomatic mother with COVID-19. Breastfeed Med. (2020) 15:488-91. doi: 10.1089/bfm.2020.0161

26. Cheema R, Partridge E, Kair LR, Kuhn-Riordon KM, Silva AI, Bettinelli ME, et al. Protecting breastfeeding during the COVID-19 pandemic. Am J Perinatol. (2020). doi: 10.1055/s-0040-1714277. [Epub ahead of print].

27. Dumitriu D, Emeruwa UN, Hanft E, Liao GV, Ludwig E, Walzer L, et al. Outcomes of neonates born to mothers with severe acute respiratory syndrome coronavirus 2 infection at a large medical center in New York City. JAMA Pediatr. (2020). doi: 10.1001/jamapediatrics.2020.4298. [Epub ahead of print].

28. Conzelmann C, Groß R, Meister TL, Todt D, Krawczyk A, Dittmer U, et al. Holder pasteurization inactivates SARS-CoV-2 in human breast milk. SSRN Electron J. (2020). doi: 10.1101/2020.06.17.155689

29. Walker GJ, Clifford V, Bansal N, Stella AO, Turville S, Stelzer-Braid S, et al. SARS-CoV-2 in human milk is inactivated by Holder pasteurisation but not cold storage. J Paediatr Child Health. (2020). doi: 10.1111/jpc.15065. [Epub ahead of print].

30. WHO. Breastfeeding and COVID-19. (2020). Available online at: https://www. who.int/publications/i/item/10665332639 (accessed July 21, 2020).

31. UNICEF. Breastfeeding During the COVID-19 Pandemic. (2020). Available online at: https://www.unicef.org/eap/breastfeeding-during-covid-19 (accessed July 21, 2020). 
32. CDC. Coronavirus Disease 2019 (COVID-19): Care for Breastfeeding Women. (2020). Available online at: https://www.cdc.gov/ coronavirus/2019-ncov/hcp/care-for-breastfeeding-women.html (accessed July 21, 2020).

33. Royal College of Obstetricians and Gynaecologists. Coronavirus (COVID-19) Infection in Pregnancy. Version 10.1 (2020).

34. Dong Y, Chi X, Huang H, Sun L, Zhang M, Xie W-F, et al. Antibodies in the breast milk of a maternal woman with COVID-19. Emerg Microbes Infect. (2020) 26:1-12. doi: 10.1080/22221751.2020.1780952

35. Fox A, Marino J, Amanat F, Krammer F, Hahn-Holbrook J, Zolla-Pazner S, et al. Evidence of a significant secretory-IgA-dominant SARS-CoV-2 immune response in human milk following recovery from COVID-19. medRxiv. (2020). doi: 10.1101/2020.05.04.20089995. [Epub ahead of print].

36. Preßler J, Fill Malfertheiner S, Kabesch M, Buntrock-Döpke H, Häusler S, Ambrosch A, et al. Postnatal SARS-CoV-2 infection and immunological reaction: a prospective family cohort study. Pediatr Allergy Immunol. (2020) 31:864-7. doi: 10.1111/pai.13302

37. van Keulen BJ, Romijn M, Bondt A, Dingess KA, Kontopodi E, van der Straten $\mathrm{K}$, et al. Breastmilk; a source of SARS-CoV-2 specific IgA antibodies. medRxiv. (2020). doi: 10.1101/2020.08.18.20176743. [Epub ahead of print].

38. Ceulemans M, Hompes T, Foulon V. Mental health status of pregnant and breastfeeding women during the COVID-19 pandemic: a call for action. Int $J$ Gynaecol Obstet. (2020) 151:146-7. doi: 10.1002/ijgo.13295

39. Zanardo V, Manghina V, Giliberti L, Vettore M, Severino L, Straface G. Psychological impact of COVID-19 quarantine measures in northeastern Italy on mothers in the immediate postpartum period. Int J Gynaecol Obstet. (2020) 150:184-8. doi: 10.1002/ijgo.13249

40. Davenport MH, Meyer S, Meah VL, Strynadka MC, Khurana R. Moms are not OK: COVID-19 and maternal mental health. Front Glob Womens Health. (2020) 1:1. doi: 10.3389/fgwh.2020.00001

41. Nichols J, Schutte NS, Brown RF, Dennis C-L, Price I. The impact of a self-efficacy intervention on short-term breast-feeding outcomes. Health Educ Behav. (2009) 36:250-8. doi: 10.1177/10901981073 03362

42. Dennis C-L, McQueen K. The relationship between infant-feeding outcomes and postpartum depression: a qualitative systematic review. Pediatrics. (2009) 123:e736-51. doi: 10.1542/peds.2008-1629

43. Da Silva Tanganhito D, Bick D, Chang Y-S. Breastfeeding experiences and perspectives among women with postnatal depression: a qualitative evidence synthesis. Women Birth. (2020) 33:231-9. doi: 10.1016/j.wombi.2019.05.012

Conflict of Interest: LM, NS-H, and SL are employees of Medela AG, Switzerland.

Copyright (C) 2020 Mitoulas, Schärer-Hernández and Liabat. This is an open-access article distributed under the terms of the Creative Commons Attribution License (CC $B Y)$. The use, distribution or reproduction in other forums is permitted, provided the original author(s) and the copyright owner(s) are credited and that the original publication in this journal is cited, in accordance with accepted academic practice. No use, distribution or reproduction is permitted which does not comply with these terms. 